\title{
Assembling the refugee anthology
}

\author{
Emma Bond
}

\begin{tabular}{|c|c|}
\hline Date of deposit & 16092019 \\
\hline Document version & Author's accepted manuscript \\
\hline Access rights & $\begin{array}{l}\text { Copyright (c) } 2019 \text { Informa UK Limited, trading as Taylor \& } \\
\text { Francis Group. This work has been made available online in } \\
\text { accordance with publisher policies or with permission. Permission } \\
\text { for further reuse of this content should be sought from the } \\
\text { publisher or the rights holder. This is the author created accepted } \\
\text { manuscript following peer review and may differ slightly from the } \\
\text { final published version. }\end{array}$ \\
\hline $\begin{array}{l}\text { Citation for } \\
\text { published version }\end{array}$ & $\begin{array}{l}\text { Bond, E. (2019). Assembling the refugee anthology. Journal for } \\
\text { Cultural Research, Latest Articles. }\end{array}$ \\
\hline $\begin{array}{l}\text { Link to published } \\
\text { version }\end{array}$ & https://doi.org/10.1080/14797585.2019.1665894 \\
\hline
\end{tabular}

Full metadata for this item is available in St Andrews Research

Repository at: https://research-repository.st-andrews.ac.uk/

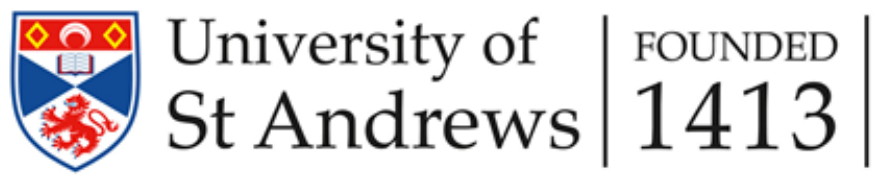




\section{Assembling the Refugee Anthology}

Abstract

There has been a sudden proliferation of short story anthologies published in response to the refugee 'crisis' of 2015 and the US travel ban of 2017. This article focuses on two of these collections (The Displaced and Banthology, both 2018) in order to ask: what makes an anthology better equipped than a single authored piece of writing to respond to contemporary themes such as migration and displacement? The answer might lie in their heterogeneous form, which allows anthologies to be assembled and reassembled by various stakeholders during their production and reception so that they mean differently in different times and places. Conceiving of the anthology as assemblage brings Deleuze and Guattari's original concept into dialogue with newer notions of queer curation and postcolonial reading, and reveals anthologising processes of selecting and fitting elements together to be deliberate tactics. In particular, these processes highlight the agentic role of the reader, which allows them to make their own assemblages from the multiple interrelations that emerge between the anthology's composite elements. Through developing this concept of assemblage reading I extend the framework of what we think of as a 'refugee anthology' to encompass a much wider range of acts of collective creation. 


\title{
Assembling the Refugee Anthology ${ }^{i}$
}

\begin{abstract}
'In a book, as in all things, there are lines of articulation or segmentarity, strata and territories; but also lines of flight, movements of deterritorialization and destratification [...] All this, lines and measurable speeds, constitutes an assemblage.' (Deleuze and Guattari, A Thousand Plateaus, p. 4)
\end{abstract}

\section{Introduction}

'Jujube', Ubah Cristina Ali Farah's disturbing fantasy story in the 2018 collection Banthology, tells of a medicine woman in Somalia who works with herbs and roots to protect her family and fellow villagers against disease, threat and sorcery. The medicine woman and her two daughters (of which one, Ayan, is the narrator) all share one striking characteristic: their hair.

Mama extracts gelatine from the leaves of the Jujube tree - the only soap or shampoo we're allowed to use - then sprinkles us with frangipani water and braids multicoloured ribbons into our hair. The wind transforms it into long vines filled with flowers. And thanks to her treatments, our hair has grown in extraordinary ways, black and lustrous like ebony, the fibres as ductile and strong as gold. (Cleave, 2018, p. 38)

The jujube stands as the most sacred resource within Ayan's mother's toolkit of medicinal cures and - as with the hair treatment described above - its essence seems to knit into the folds of the human body itself to achieve new forms of beauty and even pathways toward salvation. As Ayan's mother believes: "Whoever dies with jujube seeds in their body goes directly to heaven"' (Cleave, 2018, p. 39). This state of harmony between human and nature is disrupted by the outbreak of the Somali civil war which ends up separating the family: a rupture that is reflected in the structure of the story itself. Ayan's memories of the past are subsequently interrupted by a series of 'interpreter's notes' which reveal a supplementary narrative of trauma and intersect with her impressions of the present moment. Writing now as a refugee in Italy, Ayan's engagement with nature takes on a different form. The world appears to her to be 'encased in ice', 'barren', 'the trees have a funereal look' (Cleave, 2018, p. 40), and the plants she sees growing in gardens have no purpose aside from mere decoration.

I propose using this powerful metaphor of the jujube in Ali Farah's story as a way to unlock the narrative purpose of the emerging genre of what I will call here the 'refugee anthology'. I use this term to mark the sudden proliferation of short story anthologies published in response to the refugee 'crisis' of 2015, and the subsequent US travel ban of 2017, including Home Truths (2015), A Country of Refuge (2016), Refugees Worldwide (2017), A Country to Call Home (2018), The Displaced (2018), Banthology (2018), and many others. This article will focus on the last two collections on this list in order to think through the logic behind this emergence of the refugee anthology as both narrative form and technique and to interrogate the meaning of its growing success. What is it that such anthologies offer that goes beyond a single authored piece of fiction or non-fiction dealing with the same themes of migration and 
displacement? And how are they assembled by various stakeholders at different stages in production and reception processes in such a way that enables them to offer diverse sets of meaning to different readers? In answering these questions, my article will seek to define and nuance the notion of the assemblage as a set of individual and collective tactics that carry meaning making capacity. I then situate the notion of the assemblage within existing anthologies criticism, and look to identify some specific processes of assembling and reassembling that are carried out by editors, publishers, and readers of such collections. Here, this unfolds through close comparative readings of material contained within and across the collected stories that illustrate the way these assembling tactics work: through playful modes of reading that establish connections through heterogeneity, affective mapping, and alternative modes of communicating across boundaries, such as - for example - through the expression of shared corporeal experiences. Assembling meaning is seen here as a project of curation, but also potentially of cure, and in conclusion, I seek to broaden out the definition of the 'refugee anthology' to encompass a much wider range of collective creative acts.

The first act of curation (my own) lies in the selection of the two texts to use as exemplary material for comparison here. Both collections were published in same year (2018), both are made up of stories that were - in the main - written especially for the anthologies in question, and both were designed with a civic function in mind. ${ }^{\text {ii }}$ The first, Banthology, was published by Comma Press, a small UK publishing house, and was commissioned and assembled by the editor of the publishing press itself, Sarah Cleave. Some of the authors featured in Banthology had already been published by Comma Press, others were new additions to its catalogue. Cleave was later contacted by Deep Vellum Publishing, a not-for-profit literary arts organization based in Texas, who publish first-time English language translations of works by contemporary international writers, and the two presses decided to co-publish US and UK versions of Banthology in tandem. The Displaced, on the other hand, was published by the relatively large US-based Abrams Press, edited by renowned refugee writer Viet Thanh Nguyen and contains seventeen stories, some by very high profile writers (such as Ariel Dorfman, Aleksandar Hemon, Marina Lewycka and Maaza Mengiste). These contrasting features have led to inevitable differences in the way the collections were distributed and received. A much slimmer volume (containing only seven stories) and originally published in paperback, Banthology lacks the cultural heavyweight of Nguyen as editor, and as such was probably destined from the start to have a much smaller global circulation and to attract less critical attention. To be sure, Nguyen's fame itself functions as part of an intentional marketing strategy for The Displaced: his name is a prominent endorsement on the book cover, as is mention of the Pulitzer prize he was awarded for his own narrative work. The success of the original hardback of The Displaced has also resulted in a new paperback edition, which was issued by Abrams in April 2019 with a different cover image and two additional essays (Nigerian American author Chris Abani's 'The Road', and Palestinian lawyer and writer Raja Shehadeh's 'Am I a Refugee?').

Yet modes and tactics of assembling also inevitably shape and inform our own choices as comparatist scholars. When reflecting on my own reasons for selecting Banthology and The Displaced as the primary texts of analysis here, I identify with Gayatri Gopinath's description 
of such practices as acts of 'queer curation', which seek not only to produce alternative histories by means of new juxtapositions, but also acknowledge a certain level of personal investment in selection processes, and indeed even of mere 'happenstance' (2018, p. 4). My own prior familiarity with writers involved in these two collections, such as Ubah Cristina Ali Farah and Maaza Mengiste, made me turn to these volumes first on my personally assembled list of anthologies, and also doubtless affected my own reading and approach to both. I want to use my own readerly experience here to think through the multiple layers of intentionality that are particularly resonant in the assembling of anthology texts and which might combine or even clash to produce quite different modes of 'assembled' reception in different cases. First, though, I will return to the metaphor of the jujube that opened this article in order to shed light on how to approach the anthology as a methodology in itself, and - in so doing - explore how it can ultimately function in the mode of an assemblage.

For the jujube emerges as a powerful narrative conductor in Ali Farah's text even beyond its overtly curative properties. Fleeing from pursuit as her village is ransacked by hostile armed forces, Ayan comes across the familiar tree and hugs it in an attempt to hide herself and find sanctuary.

And suddenly I see a fluorescent wake envelope me completely. My hair takes on the form of the jujube's spiky branches, it grows abundantly, hanging down towards the ground until covering me completely. My hair sprouts jagged and luminescent leaves and little white flowers in the shape of stars. The dogs howl around the base of the jujube but they can no longer see me. (Cleave, 2018, p. 44)

The description of this metamorphosis, the kinetic, sympathetic melding of two elements into one heterogeneous structure that holds new capacities, yields new insight into how we might read transnational texts such as the refugee anthology. Elsewhere I have used the idea of collage, or cultural bricolage, as an illustration of how the transnational works as a methodological or stylistic choice (Bond, 2020). In particular, I have drawn on Lévi-Strauss's concept of the bricoleur, which describes someone who makes new things from materials at hand. These are things that are already there, and 'which had not been especially conceived with an eye to the operation for which they are to be used' (Derrida, 2001, p. 360). The bricoleur is, therefore, someone who constructs by means of association. But analysing the complex form of the anthology demands attention to the concept of assemblage, as defined by Deleuze and Guattari (2004), and elaborated by critics such as Jasbir Puar (2007), Aihwa Ong (2008) and Manuel DeLanda (2016). Assembling is a more intentional, less associative action than that of bricolage, one that involves processes of deliberately selecting, matching or fitting together a set of components to produce 'an ensemble of parts that mesh together well' (DeLanda, 2016, p. 1):

It is a multiplicity which is made up of many heterogeneous terms and which establishes liaisons, relations between them, across ages, sexes and reigns - different natures. Thus, the assemblage's only unity is that of a co-functioning: it is a symbiosis, a 'sympathy'. It is never filiations which are important, but alliances, alloys; these are not successions, lines of descent, but contagions, epidemics, the wind. (Deleuze, 2006, p. 52) 
The assemblage thus functions through flows rather than through heritage or lineage, linking it intimately with themes of mobility and migration through its attention to modalities of speed and lines of flight. And it becomes especially resonant here because the example that Deleuze and Guattari use to illustrate the notion of the assemblage is precisely that of the book. But not every book will be rhizomatic in the nature of its assemblage. Some (most, even) still adhere to a taproot or arborescent model, and are thus built around fixed models of signification which reproduce existing binaries and hierarchies. The rhizomatic assemblage, on the other hand, no longer follows a standard process of dividing external reality, book and author from one other, and instead establishes 'connections between certain multiplicities drawn from each of these orders' (Deleuze \& Guattari, 2004, p. 25). It is, therefore, not an image of the world, but an assemblage with the world, and is capable of forming new assemblages in turn. I argue that even considered on its own, Ali Farah's story 'Jujube' encourages just this kind of rhizomorphous reading. Ayan's metamorphic intervention alters both her own state and the state of the tree, transforming a binary relation to a multiple one, since 'an assemblage in which components have been correctly matched together possesses properties that its components do not have' (DeLanda, 2016, p. 5). This allows both parties to take on additional virtual tendencies and capacities in the process. The fantastical element of this co-functioning sees both elements 'decentred onto other dimensions,' (DeLanda, 2016, p. 8) in just the sort of symbiosis, or 'sympathy,' that Deleuze mentions in the citation above. But Ayan's metamorphosis in 'Jujube' also recalls Jasbir Puar's attention to the processes of melding, fusing, and viscosity that characterise the assemblage. This is because 'assemblage is more attuned to interwoven forces that merge and dissipate time, space, and body against linearity, coherency, and permanency' (Puar, 2007, p. 212). Ayan's traumatic experience of displacement, and the psychological ellipsis that her fantastical metamorphosis affords her, are reflected in the shattered linearity of the final narrative structure of 'Jujube' - something that demands we interrogate the effects of literary assemblage on the reader, and on the reading process, in turn.

Yet beyond its function in this individual story, I argue that we can identify different modes of assemblage across a series of texts in collections such as The Displaced and Banthology that will perhaps help us to formulate ideas around possible new geographies of the book. The assemblage is an effective way of conceiving of inherently transnational collections such as these not simply because they bring together authors from various different places, but because of the multiple lines and interrelations that such juxtapositions allow to emerge. This occurs not only through the assembling actions of commissioning stories, editing collections, or marketing them for various publics worldwide. It also occurs through practices of transnational assemblage reading. My own readings across these two anthologies will therefore show where Deleuze and Guattari's principles of assemblage might emerge within them (the principles of connection, heterogeneity, multiplicity, asignifying rupture, cartography and decalcomania), but will also look beyond these underpinning ideas towards new critical visions. For I believe that addressing the highly-politicized topic of migration that forms the basis of the collections at hand demands an engagement with postcolonial and queer readings of assemblage - where queer is envisaged as a 'dissenting, resistant, alternative' mode of approach (Puar, 2007, p. 205) and postcolonial readings can be equally 'subversive and transformational' (Boehmer 2017 , p. 14). In these collections, practices of assembling and curating must be identified in the various temporal moments of production and reception, and in doing so, the very tactics of 
pulling things together (or apart) that characterise each of these phases become inherently political in themselves. For carefully compiled, specially commissioned texts like Banthology and The Displaced hold a complex, intra-connected structure which yields multiple entry (and exit) points for the reader to choose from. There may well be fixed narrative beginnings, middles, and ends in the way these texts have been put together, but there is no guarantee that the reader will conform to them (and indeed, this is mimicked in the topsy-turvy title of the opening story in The Displaced, Joseph Azam's 'Last, First, Middle'). The stories included within these collections contain dimensions and directions that can be connected and combined for meaning-making purpose, not - as Deleuze and Guattari say - through points or positions, but through lines (2004, p. 9). So beyond thinking about the assemblage as a useful way of conceptualizing the structure of the refugee anthology, I will also pick up on multiple examples of how the assemblage functions as a subject or theme in order to form links between the stories included within them. I will conclude that the refugee anthologies under discussion here can function as examples of rhizomatic assemblages in that they can be read trans-dimensionally and transnationally, in a new mapping exercise of (im)mobility routes and thus also 'of realms that are yet to come' (Deleuze \& Guattari, 2004, p. 5).

\section{Assembling Anthologies}

As Leah Price points out in her 2000 work The Anthology and the Rise of the Novel, there are remarkably 'few theories of the genre of anthologies' (p. 2). Most existing work deals with anthologies in their traditional sense of compiled collections of excerpts or abridged versions of canonical texts rather than, as here, series of short stories that have been commissioned specifically for the purposes of forming new (often thematic) collections. For this reason, the main critical concern to date has been with interrogating the relationship between the anthology and its canon-making capacity (see, for example: Gorak 1991, Guillory 1993, Kaplan \& Rose 1996, and Lauter 1991). Yet Price believes that due attention has not yet been paid to the technical, manual work that goes into processes of editing, abridging, and compiling, and that because of this work, the genre of the anthology in all its forms conceals a wide potential for meaning-making across various areas of interest. For one, the processes of selection and ordering involved in compiling such collections reveal potential tensions within the arena of intentionality and response. As Price explains, the aim of the traditional anthology is to be wholly representative of a genre, period or group of writers: something that is undermined by the obvious processes of selection that the finished compilation embodies $(2000$, p. 6). It is perhaps then up to the individual stories themselves to retain a sense of attentiveness to the gaps brought about by such strategies of inclusion and exclusion. To prove this point, Aleksandar Hemon's 'God's Fate', in The Displaced, tells the story of Kemalemir Frashto, a Bosnian refugee he met in the United States, and of the multiple traumas and displacements Frashto faced during and after the 1992 conflict in his homeland. Yet Hemon acknowledges that including Frashto's narrative in his story means inevitably that another person's life story will not be written or read, yet he uses this point to prove the importance of 'individual narrative enfranchisement' (Nguyen, 2018, p. 92, emphasis added) for a greater understanding of the whole. Hemon's point about the power of small, or individual interventions is beautifully illustrated within his retelling of Frashto's story, when he explains the significance of being shown an intricately crocheted beige tablecloth made by Kemalemir's mother. The only item 
Frashto retains from his family home after it was ransacked by their Serb neighbours, the tablecloth holds the entire history of the family's disenfranchisement, but also of Frashto's own escape and the resolution of his personal story. One detail in particular stands out:

In Charlotte, Kemalemir showed me the circular area where his mother had used white thread when she'd run out of the beige kind. The shift in color was so subtle I would've never noticed if he hadn't pointed it out to me. "This thing, this small thing," he said, "is what makes it unique." (Nguyen, 2018, p. 104)

Like the material canvas of the crochet here, I envisage the individual stories in these collections functioning as narrative maps that can be 'torn, reversed, adapted', and that are 'susceptible to constant modification' (Deleuze and Guattari, p. 13) depending on how they are assembled and re-assembled at various stages of their production and reception, allowing them to mean differently in different places and to different readers.

Yet on a macro-level, the anthology is also subject to ulterior practices of intentional selection on the part of editors and publishers that might risk allowing one particular history to emerge instead of another. It thus also runs the risk of fixing history into that one image that it has decided to communicate, and in so doing, might unintentionally end up 'fixing' cultural difference as well. Again, this issue asks us to consider our own practices as readers of such collections, and to ask ourselves to 'what vision of cultural production does the making and the reading of this anthology commit us' (Mason, 1998, p. 187). This is certainly the case with the two anthologies under examination here, both of which were commissioned with the specific aim of formulating a direct response to President Trump's 2017 'travel ban'. In the case of Banthology, the idea originated within the publishing house itself. The idea Comma had was to compile a volume which featured writers from each of the seven 'banned', Muslimmajority countries (Iran, Iraq, Libya, Syria, Somalia, Sudan and Yemen) in what has been termed a 'short but effective act of resistance' to the discriminatory regulations set in motion by the US (Riggs, 2018). This aim is, in fact, mirrored in the structure of the book, where the stories are labelled according to the country that they are here to represent (whereas in The Displaced, the stories are presented by the alphabetical order of their authors' surnames). Viet Thanh Nguyen has discussed similar editing decisions in the case of The Displaced in an interview published in the LA Review of Books. Nguyen was approached by the editor of Abrams Press, Jamison Stoltz, around the time of Trump's 'travel ban', because Stoltz wanted to 'do a book about refugees' [sic]. This was because the ban had allowed a hitherto unknown family circumstance to emerge: namely that Stoltz's wife had, in fact, entered the United States as a refugee herself. Stoltz came up with half the writers for the collection, Nguyen the other half: the only criterion they used was that the people involved had to be both refugees and writers. They were not looking for oral history accounts of the refugee experience - they wanted written stories by published authors. 'We thought writers who had been refugees could bring both the artistry and the emotion - and the history - to what they were telling' (Buckley, 2018). Of course, Nguyen is a refugee himself, and it is important to note that the element of including personal experiences was key for the ideation of both volumes. But Nguyen's personal editorial choices can also be seen to leave other traces in the collection - the presence of multiple Vietnamese-American writers, for example, and the suggestion of future French and Vietnamese editions (Buckley, 2018). 
Another layer of intentionality is visible within the processes of marketing that assemble the books as saleable products. The cover of the original hardback edition of The Displaced is coloured a striking bright yellow, and features one single image of a red life jacket. This cover must surely re-evoke the highly-publicised rise in migrant boat crossings over the Mediterranean since 2015, and suggests thematic synergies with recent artworks of response, such as the 14,000 life jackets discarded by migrants on the Greek island of Lesbos that Ai Weiwei installed on the façade of Berlin's Konzerthaus in 2016. ${ }^{\text {iii }}$ In contrast, the UK version of Banthology's cover art depicts a figurative mesh of barbed wire dissolving into birds, illustrating the book's stated aim to subvert existing boundaries through the freedom of literature. The US version is more literal, the cover showing a stylised hand holding a book with a banned sign superimposed over it. By aligning the anthology with the migration 'crisis' of 2015 through the ultimate symbolic image of the discarded lifejacket, The Displaced joins a developing global critical discourse that re-assigns power to personal objects that can narrate refugee lives differently (see Barry, 2019). In fact, Idalina Conde (2012) suggests we see such artworks as assemblages 'of objects, artistic intention, and newly enrolled attentions from potential audiences,' which bring about new agencies, new meanings and new associations (Barry 2019, p. 208). But Banthology retains different traces of the global through an attention to translation, since only two of the stories included were originally written in English (as opposed to The Displaced, where all of the stories were written directly in English). The translators of the stories in Banthology are, unusually, given equal attention to the writers themselves in the brief biographies section provided at the back of the book. But if we are to categorise both books as 'global assemblages' (albeit in different ways), critics such as Rebecca Walkowitz would urge us to think not only about the language of composition (both visual and textual), but also about languages of circulation - also in relation to subsequent strategies of translation, or indeed to reception. This becomes especially resonant when we are dealing with works that 'theorize their own cultural mobility' through an attention to practices of transnational migration and movement (Walkowitz, 2006, p. 531). And where, in the case of refugee anthologies such as The Displaced and Banthology, the authors involved will most likely be from multiple different places, have travelled through multiple other places, and now reside somewhere completely different. As Walkowitz says, this is important, because:

(O)ne may not fit comfortably in any system; and one does not necessarily give up past affiliations while forging new ones. [...] These ways of thinking about the varieties and complexities of literary participation correspond to new ways of thinking about whose lives and which objects are transformed by migration. (2006, p. 531, emphasis added)

This sense of transformation that characterises the assemblage of refugee lives and stories is picked up in Vu Tran's story for The Displaced, 'A Refugee Again'. Tran asserts that as a refugee subject she has been forced to develop different versions of herself, to learn to speak in different languages at different times, even to change her name according to particular circumstances. She concludes that her own refugee status (and that of millions of others in her position) 'requires an adjustment and perhaps a transformation of who she is':

The imperative of acculturation demands personal fluidity, the ability to be more than one person. Which is why a refugee is also like an actor. She knows she must assimilate 
in order to earn acceptance, to survive and prosper, but the act of assimilation is inevitably a performance - not of a false or superficial identity necessarily, but of one more legible to her audience. (Nguyen, 2018, p. 153)

The trajectories of the stories included in these collections can be seen to mimic the mechanics and mobilities of refugee lives in their propensity toward fluidity and their ability to shift and change according to altered contexts of assemblage at various points in their production and reception. Yet it is important to reflect on the fact that, at the same time, the most visible of these published collections exist only in English (for now), thus limiting the range and scope of their circuits of transnational and translingual mobility.

Beyond the intentional assembling actions of commissioning and marketing, writing and translating, we must also consider the intentionality of the editors' own positions. The aims of the two editors here were, perhaps unsurprisingly, very similar, and both are stated quite clearly in the prefaces to the works. The Displaced aspires to highlight the connections between migration and other global issues (such a climate, war, drugs, consumerism), to correct the disempowerment of refugees, and to address differences in the opportunities available to refugees to tell their own stories. In the 'Introduction', Nguyen also expresses a desire for writing to 'perform some justice for those compelled to move' (2018, p. 18), and to in some way 'speak for the voiceless' (2018, p. 19). Acknowledging nonetheless the problematics of this mechanism, Nguyen goes on to clarify that it is the global system of multiple entrenched inequalities that renders people 'voiceless' within a system that silences rather than assuming those people to be literally without voice (2018, pp. 19-20). Cleave also references the potential for Banthology to 'give voice' to that set of nations affected by the US travel ban (2018, p. vii). Cleave appears to imagine that generating a fictional response to the ban would, in a sense, upturn it through the experience and understanding of reading as a form of travel in itself. Both collections also accentuate the difference between the individual stories and styles of narration that they include, and the alternative narratives and perspectives involved, thus highlighting the multiplicitous nature of their composition. Banthology covers a range of approaches: from satire, to allegory, to literary realism; The Displaced contains two graphic panels by Vietnamese born comic artist and writer Thi Bui, and recounts Fatima Bhutto's experience of a virtual reality migrant performance installation. Both books therefore follow a model of assemblage through this principle of multiplicity, and have been edited into a series of 'plateaus' that communicate with one another across 'microfissures', rather than into chapters that hold fixed 'culmination and termination points' (Deleuze and Guattari, 2004, p. 24).

When viewed all together, these processes of assemblage (commissioning, marketing, translating and editing) have a significant impact on the structure and form of the collections, and will also have knock-on effects on the reader and their own experience of the text(s). An encounter with a cut and paste assemblage of shorter texts of disparate styles (such as the anthology) forces readers to 'surface periodically from the self-indulgent pleasures of mimesis to a higher, less particularized, more disinterested plane' (Price, 2000, p. 7). Such an operation recalls the premise for Maaza Mengiste's story in The Displaced, 'This Is What the Journey Does', in which the Ethiopian-American writer surfaces from her own writing in a café in Florence to watch the disordered behaviour of a young, fellow East African, migrant in the street outside. The suggestion is that the young man is traumatised and disturbed by the 
migration journey he has undertaken, and part of what captivates Mengiste in the unfolding scene is the constant motion of his body (which in turn recalls Brian Massumi's line of thought on the perpetual motion of assemblages, cit. Puar, 2007, p. 213). Mengiste describes this motion as a 'spastic energy', a sense that the migrant she observes is breaking, and re-arranging himself in order to keep himself together (Nguyen, 2018, p. 132). And indeed, her own empathetic reading of the situation, her perception of a series of intimate connections with the figure of the migrant, in turn forms the basis for the layers of construction and composition that make up this new story.

Expanding the potential for more 'conscious' readings such as Mengiste's might also encourage the readers of these anthologies to make their own relations and connections within the body of the volume, which will again have a significant impact on the intra-relational network of the texts, and on the reader's experience of them. As discussed, when reading an anthology, the reader can pick which order to read the collected stories in: you can skip stories, go straight to a particular one of interest. Perhaps (as in my own experience) you know the author already from previous works, or you've read a review, or you have an interest in one theme or nation represented therein. In other words, there is a playful element of controlled assemblage or cultural collage on the part of the reader, that may not coincide with any of the structures of top-down intentionality described above. These practices recall De Certeau's well-known work on the reader as traveller, or poacher - a reader who maps new landscapes of text according to what interests him, and forges new connections between sometimes disparate elements through his own modes of invention and design.

In fact, to read is to wander through an imposed system (that of the text). [...] The reader invents in texts something different from what they "intended". He detaches them from their (lost or accessory) origin. He combines their fragments and creates something un-known in the space organized by their capacity for allowing an indefinite plurality of meanings. (De Certeau, 1984, p. 169)

In De Certeau's imaginary, readers themselves use texts to 'miniaturize and collate a world' (or at least their understanding of a world), thereby introducing elements of 'plurality and difference into the written system of a society and a text' (1984, p. 173). They can add or subtract meaning from a text, undermining its relation to previously fixed times and places through a more fluid spatiality of reading.

This potential for playful reading can be identified through exploring how the individual stories within the two collections might allow the reader to form connections and relations across the structure of the text as a whole. This allows us to further understand these particular collections as assemblages, since we will be able to use these networked relations as a means to 'explore the heterogeneous within a structure' (Marcus and Saka, 2006, p. 102), but also to synthesize the multiplicity of the available elements without effacing that same heterogeneity. A good illustration of this project is Joseph Kertes' description of Canada as a 'salad' or 'mosaic' in contrast to the 'melting pot' of the United States in his story 'Second Country' (Nguyen, 2018, p. 111). As a Hungarian-Jewish-Canadian refugee, Kertes feels that Canada has allowed him to retain his multiple, hyphenated, original identities in parallel. His affirmation here is a good example of how the macro-structure of the texts in question function, and relates also to 
Nguyen's 'Introduction' to the same volume, in which he remarks on his desire for borders to be permeable, not rigid, and yet still to act as 'markers of culture and identity, valuable but easily crossed' (2018, p. 19). This motif crops up once again in Ariel Dorfman's 'How Succulent Food Defeated Trump's Wall Before It Has Been Built', in the description of an international grocery store in the author's North Carolina hometown, which goes by the suggestive name of COMPARE. The store forms a network of gastronomic alliances that not only permit Dorfman to retrace his own historical passage through various Latin American countries, but also to form new imagined links with multiple home and diasporic communities through the materiality of food.

To stroll up and down the grocery aisles [...] is to reconnect with the people and the lands and the tastebuds of those brothers and sisters and to partake, however vicariously, in meals being planned and prepared at that very moment in millions and millions of homes everywhere in the hemisphere. (Nguyen, 2018, p. 62)

The idea that principles of connection and heterogeneity can be found in the sensory experience of assembled difference mirrors Deleuze and Guattari's insistence that in a rhizomatic assemblage, 'any point can be connected to anything other, and must, and that the rhizome itself 'ceaselessly establishes connections' (2004, p. 7; p. 8). ${ }^{\text {iv }}$ But it also aligns with Jonathan Flatley's notion of affective mapping, which allows the individual to historicize their own affective experience and resituate it in the present, in relation to the experiences of others (2008, p. 4). What I think aligns Flatley's concept of mapping to my analysis here is that it does not aim to establish a fixed territory, but rather to provide 'a feeling of orientation' (2004, p. 7) and to facilitate further mobility of thought. It is revisable, relational and transformative, assembled or 'cobbled together in processes of accretion and palimpsestic rewriting from other persons' maps' (2004, p. 78). As such, it also provides a generative idea of what playful, conscious readings might achieve within the framework of the anthology assemblage.

But although in this system reading might become so connected and connectable that it appears to no longer rely on fixed locations of meaning, we must still be attentive to individual cartographies of reading that are established through global networks of production, translation, circulation and comparison (see also Walkowitz, 2006, p. 543). Fixed points take on a new importance if we can map a constellation of positionalities that allows us to think about where stories are being read, and where they are being talked about, 'where they are classified and given social purpose' (Walkowitz, 2006, p. 527), from the embodied perspective of readers themselves. Privileging different forms of readership and reception in this way recalls Rita Felski's work on modalities of (self-) recognition in encounters with books, in which she borrows Stephen White's phrase 'sticky selves' to describe how 'rather than being frictionless, disembodied and detached, (readers) are caught up in the particulars of time and space, of culture and history, body and biography' (Felski, 2008, p. 42). And it is precisely through the encounter with an other, or with otherness (in person, or through contact with an external artwork such as a book), that we can bring this encounter back to a bodily level. Flatley uses Adorno's notion of the 'shudder' precisely to describe the sensation of self-estrangement that follows an aesthetic encounter and accompanies a return to subjectivity and everyday life (2008, p. 82). This allows us to conceive of the body as an active point of reception and 
transmission within networks and lines of reception, and thus as an affective assemblage in itself (see also Puar, 2007, p. 211).

Indeed, in these stories, bodily sensations bear witness to the pain and dislocation of the refugee experiences of others, as part of a framework of stickiness or interconnection that may also be accessible to the reader. This is the idea behind the story 'Flesh and Sand' by Fatima Bhutto, which describes her visit to Alejandro G. Iñárritu's award-winning virtual reality installation Carne y Arena at the Fondazione Prada in Milan. In this installation, visitors are given the chance to 'experience' crossing the border between Mexico and the United States - they have to be alone, to walk barefoot, and to encounter 'migrants' in the VR landscape because, as Iñárritu says, 'Your body never lies' (cit. in Nguyen, 2018, p. 48). The potential imagined here for the transfer of experience through affect speaks to Puar's conception of assemblage as underscoring the primacy of 'feeling, tactility, ontology, affect and information' (2007, p. 215). In a similar vein, Maaza Mengiste's 'This Is What the Journey Does' tells of her sighting of an East African migrant in Florence as she sits in a café, and how she experiences an 'ache' in the middle of her chest that binds her to him, in a corporeal connection she feels is so strong that she is sure he can feel it too:

I am certain it is a tether binding us together and he will turn in just the right way and I will be exposed. If he looks at me, then our lives will unfold and in front of us will be the many roads we have taken to get to this intersection in Florence and we will reveal ourselves for what we are: immigrant, migrant, refugee, African, East African, black, foreigner, stranger, a body rendered disobedient by the very nature of what we are. (Nguyen, 2018, p. 132)

Mengiste's fear of the 'exposure' of her own past allows an unfolding acknowledgement of the shared refugee history that binds the two people together in unseen ways in the scene described. In other stories within the two collections, bodies similarly provide access points to help to understand others' experiences, and communicate their stories, thus functioning as 'a portable map, a kind of global positioning device that tells you where you are at this particular moment, giving you a satellite view of your own life' (Flatley, 2008, p. 84). And they can likewise themselves act as repositories of memories and constitute alternative forms of communicating the pain and trauma of exile.

In moments when several who made the journey were gathered, I would watch them point to their scars to help fill the lapses in their stories. Sometimes, there was no language capable of adding coherence to what felt impossible to comprehend. Sometimes, it was only the body that bore the evidence, pockmarks and gashes forming their own vocabulary. (Nguyen, 2018, p. 133)

Similarly, Fereshteh Molavi's 'Phantom Limb' tells the story of one of the narrator's flatmates, Farhad, who experiences strong phantom pain when his mother's leg is amputated back home in Iran (Cleave, 2018, p. 24). These are tingling physical sensations that themselves cross borders, as 'bodies interpenetrate, swirl together, and transmit affects and effects to each other' (Puar, 2007, p. 205). The interpersonal contact suggested here is important for an understanding of affective assemblages, because as Flatley says, whilst it can be 'imaginary in 
one sense', 'inasmuch as it is based on the shared historicity of that affective life, it is quite real' $(2008$, p. 84). As such, whilst the circuits of affect described here involve different agents within the stories, one might argue that the reader could also become imbricated within these circuits through modes of contact that are facilitated by the conscious modes of reading described above. For if you can curate your own order, speed and direction of your readings of a series of texts, you might well feel more ownership of your response to them. Indeed, citing Erica Lehrer and Cynthia E. Milton, Gopinath reminds us that the root meaning of curating is caring for: "this connection demands that we think of curation "not only as selection, design, and interpretation, but as care-taking - as a kind of intimate, intersubjective, interrelational obligation," an obligation to deal with the past in particular' $(2018$, p. 4). Crucially, Gopinath finds that this act of 'caring for' can take the form of writing - I would add that is might also occur within the practice of reading, in the active, playful and conscious modes that the refugee assemblage-anthology allows.

Curation can take the form of tactics too, and in Joseph Azam's 'Last, First, Middle', the practice of curating the narrative of one's own identity can also be seen as curative. The opening story in The Displaced, it tells the tale of the author's family migration from Afghanistan, through India and Germany, and finally on to the United States. Named Mohammad Yousuf by his late grandfather, Azam considers this to be both a gift and a burden and is consistently troubled by his foreign-sounding names - names that cannot 'pass' in the United States as 'native' (enough). He asks to be known as Yousuf (which he feels is close enough to Joseph to sound American) as he embarks on various processes of 'curating [his] identity', and 'managing otherness' (Nguyen, 2018, p. 30) in order to fit in. These tactics persist until he is finally called to register his name in order to claim derivative citizenship. In a misunderstanding with the clerk he panics and drops his forms all over floor.

As I knelt down to pull together the papers that had fallen around my feet, I was confronted by the dissonance that I had lived with for so many years. I picked up the green card with the photo of Yousuf, the wide-eyed asylum-seeker. I picked up the California driver's license with the awkward photo of Joseph [...] What I did next is simply what felt most honest. Instead of choosing between my names, I chose all of them. Joseph Mohammed Yousuf Azam. It was disjointed, redundant perhaps, but it made whole again the hopes of my grandfather and added them to my own. It didn't fit in the space provided on the form that day, but it fit the moment and it fit me. This was my American name. (Nguyen, 2018, p. 33)

Embodying the principle of asignifying rupture that defines Deleuze and Guattari's notion of the assemblage, Azam's identity curation shows that connective lines may break but will always start up again on existing or new lines. They can rebound again and again, defying destruction to create something new. This is the mechanism that I hope to have identified on a much larger scale within the refugee anthologies discussed here. Again, as we are reminded by Gopinath, new forms of relationality and affiliation take place precisely within the realm of aesthetic creation and encounter $(2018$, p. 16). Anthologies allow for this space to emerge and develop, because they proffer an invitation to their readers to participate in the narrative action and to use their own tactics of assemblage to make that space their own (see Benedict, 1996, p. 212). ${ }^{\mathrm{V}}$ Practices of exchanging meaning, interpretation and reception make these books 
potential vehicles for collective action, because of the multiple layers of assembling, disassembling and reassembling that they embody. These are works that enact, produce and perform, that 'do things in the world: they shift our vision so that alternative possibilities, landscapes and geographies come into view' (Gopinath, 2018, p. 16).

\section{Conclusion: Stitching Trees / Binding Books}

In conclusion I would like to take this line of thought further and explore what happens if we start to think about new possible ways to express the 'refugee anthology' in even bolder formats. Yinka Shonibare's 2014 exhibition The British Library is an installation of 6,328 books bound in Dutch wax printed cotton, whose purpose is to celebrate the diversity of the British population. 2,700 of the books have the names of first- and second- generation immigrants to Britain who have made significant contributions to the country's culture printed in gold leaf on their covers and spines. The spines of other books in the 'library' are nameless, suggesting that the story of British immigration is as yet unfinished and that chapters within it are still waiting to be written. The installation is designed as a space for debate: a third category of books bears the names of people who have objected to or protested against immigration. Leaving room open for future interventions is key to thinking through this artwork as a refugee assemblage, as is the potential for the public to interact with the display. As I have emphasized in relation to the book anthology, it is within the scope of the manual practices and tactics of editing, compiling, ordering and so on that specific modes of meaning-making can be located. Here, this capacity for assemblage is handed directly to the public: tablet screens are provided in the exhibition which visitors can use to scroll through and learn more about the stories behind the names, and people can also submit their own stories via the website of the installation, as well as read those of other people.

Figure 1. The British Library (2014). Courtesy of the artist. Copyright Yinka Shonibare CBE.

But what if the formation of the assemblage project was put even more firmly into the hands of multiple and diverse communities of makers, and indeed, into the hands of non-professional participants drawn from the general public? The final example I will discuss here is the Stitch a Tree project, which aimed to connect communities and individuals across the UK through giving them the opportunity to show their support for displaced people around the world. Participants were invited to stitch a tree onto cotton squares of fabric, following instructions printed on booklets written in English and Arabic, and then send them in to be arranged into a large-scale embroidery called Forest by the artist Alice Kettle.

Figure 2a. Alice Kettle, Stitch a Tree (2018). Photograph by Michael Pollard.

Textiles are employed here as a 'communicative tool to create and strengthen social bonds', and to document a shared 'sentiment of care and concern for refugees and people seeking asylum' through the medium of embroidery (Kettle, 2018, p. 10). This kind of large scale embroidery is envisaged as a 'medium of unique collaborative and sympathetic power' (Kettle, 2018 , p. 23) that allows the idea of an affective assemblage to take physical form through individual contributions sewn loosely together. Building on its suggestive links back to the 
jujube metaphor that opened this article (and indeed also to Kemalemir's crocheted memorymap in The Displaced), I argue that the Stitch a Tree project embodies those same principles of assemblage: as a non-hierarchical network, it is heterogeneous, multiplicitous, acentred, and suggests an anthologizing impulse in aesthetic material terms. But it also allows us insight into how the anthology functions as a methodology in this, its most radical iteration, by pointing beyond the layers of formal assemblage that make up its composition to show where the potential for new geographies of collective action might lie.

Figure 2b. Alice Kettle, Stitch a Tree, detail. Photograph by Michael Pollard.

\section{$\underline{\text { References }}$}

Barry, K. (2019). 'Art and Materiality in the Global Refugee Crisis: Ai Weiwei's Artworks and the Emerging Aesthetics of Mobilities', in Mobilities 14: 2, pp. 204-217.

Benedict, B. M. (1996). Making the Modern Reader: Cultural Mediation in Early Anthologies. Princeton, N.J.: Princeton University Press.

Boehmer, E. (2017). 'Differential Publics - Reading (in) the Postcolonial Novel', in Cambridge Journal of Postcolonial Literary Inquiry 4:1, pp. 11-25.

Bond, E. (2020). 'Transnational', in Transnational Modern Languages: A Handbook. Edited by J. Burns and D. Duncan. Liverpool: Liverpool University Press.

Buckley, C. (2018). "Good" Refugees, "Bad" Refugees: A Conversation in Paris with Viet Thanh Nguyen. In Los Angeles Review of Books. Web.

Cleave, S. (Ed.) (2018). Banthology. Stories from Unwanted Nations. Manchester: Comma Press.

Conde, I. (2012). 'Art and Power: Contemporary Figurations'. CIES e-Working Paper, 121, in ISCTE Instituto Universitário de Lisboa Repositório. Web.

De Certeau, M. (1984). The Practice of Everyday Life. Translated by Steven Rendall. Berkeley: University of California Press.

DeLanda, M. (2016). Assemblage Theory. Edinburgh: Edinburgh University Press.

Deleuze, G. (2006). 'On the Superiority of Anglo-American Literature', in Dialogues II. Translated by Hugh Tomlinson and Barbara Habberjam. London: Continuum.

Deleuze, G. \& Guattari, F. (2004). A Thousand Plateaus: Capitalism and Schizophrenia. Translated by Brian Massumi. London: Continuum.

Derrida, J. (2001). 'Structure, Sign and Play in the Discourse of the Human Sciences' [1966]. In Writing and Difference (pp. 351-370). Translated by Alan Bass. London; New York: Routledge.

Eloff, Aragorn. (2019). 'Wandering the Shoreline with Édouard Glissant', in New Frame. Web. 
Felski, R. (2008). Uses of Literature. Oxford: Blackwell.

Gopinath, G. (2018). Unruly Visions: The Aesthetic Practices of Queer Diaspora. London; Durham: Duke University Press.

Glissant, É. (1997). Poetics of Relation. Translated by Betsy Wing. Ann Arbor: University of Michigan Press.

Gorak, J. (1991). The Making of the Modern Canon: Genesis and Crisis of a Literary Idea. London; Atlantic Heights, N.J.: Athlone.

Guillory, J. (1993). Cultural Capital: The Problem of Literary Canon Formation. Chicago: University of Chicago Press.

Kaplan, C. and Rose, E. C. (1996). The Canon and the Common Reader. Knoxville: University of Tennessee Press.

Kettle, A. (2018). Thread Bearing Witness. Alton: the artists agency.

Lauter, P. (1991). Canons and Contexts. Oxford: Oxford University Press.

Marcus, G. E. \& Saka, E. (2006). 'Assemblage'. In Theory, Culture \& Society 23 (2-3), pp. 101-106.

Mason, T. O. Jr. (1998). 'The African-American Anthology: Mapping the Territory, Taking the National Census, Building the Museum'. In American Literary History 10: 1, pp. 185-198.

Nguyen, V. T. (Ed.) (2018). The Displaced. Refugee Writers on Refugee Lives. New York: Abrams Books.

Ong, A. \& Collier, S. J. (Eds.) (2008). Global Assemblages: Technology, Politics and Ethics as Anthropological Problems. Oxford: Blackwell.

Price, L. (2000). The Anthology and the Rise of the Novel. Cambridge: Cambridge University Press.

Puar, J.K. (2007). Terrorist Assemblages: Homonationalism in Queer Times. London: Durham: Duke University Press.

Riggs, C. (2018). Book Review of Banthology: Stories from Unwanted Nations. In World Literature Today. Web.

Shukla, N. (Ed.) (2016). The Good Immigrant. London: Unbound.

Shukla, N. \& Suleyman, C. (Eds.) (2019). The Good Immigrant USA. 26 Writers Reflect on America. London: Dialogue Books.

Walkowitz, R. L. (2006). 'The Location of Literature: The Transnational Book and the Migrant Writer'. In Contemporary Literature XLVII, pp. 527-545.

\footnotetext{
${ }^{\mathrm{i}}$ The author wishes to thank the editor of this special issue and the two anonymous readers for their feedback at draft stage. She would also like to thank colleagues from the School of Modern Languages at the University of St Andrews who read an early version of this piece and made some very valuable suggestions for its development.

${ }^{i i}$ Comma Press is a not-for profit initiative dedicated to promoting diverse new writing. It has an active outreach programme, offers internships for BAME graduates and commissions translations to lend visibility to new, often marginalized authors from across the world. Abrams committed to donating $10 \%$ of the cover price of The Displaced (a minimum of $\$ 25,000$ annually) to the International Rescue
} 
Committee, a not-for-profit organization dedicated to providing humanitarian aid, relief, and resettlement to refugees and other victims of oppression or violent conflict.

iii Ai Weiwei also produced a subsequent version of this work, entitled 'Soleil Levant', where 3,500 lifejackets were installed on the windows and façade of the Kunsthal Charlottenborg museum in Copenhagen in 2017. Paul Handley has also used discarded life jackets from Lesbos in his 2017 work 'Déplacement'. For more detailed analysis of the function of the discarded refugee object in artwork, see Barry 2019.

iv These principles of connection and heterogeneity have obvious links to Glissant's work on relations and 'échos-monde' (see Glissant 1997). Glissant builds on Deleuze and Guattari's notion of the rhizome in demanding practices of opacity in order to maintain and ensure diversity of thought, identity and belonging. In particular, his own 'book-rhizome' La terre, le feu, l'eau et les vents, draws together fragments of writings by Muhammed Ali, Ibn Arabi, Frantz Fanon, Gandhi, Montaigne, Pablo Neruda, Ovid, Ezra Pound, Shakespeare and Socrates into a 'vast cosmopolitanism of the different' (Eloff, 2019).

$\checkmark$ A further interesting example of the anthologizing impulse of this sort of collective, participatory action can be seen in the crowdfunded publication of Nikesh Shukla's The Good Immigrant (2016), an edited collection of twenty-one essays by writers exploring the experience of being black, Asian or an ethnic minority in Britain today. It reached its crowdfunding target in just three days, and led to the later crowdfunded launch of The Good Journal - a quarterly literary magazine showcasing work by artists and writers of colour, and the publication in 2019 of Shukla and Suleyman's The Good Immigrant USA. 